\title{
Examining the Effectiveness of Think-Aloud Procedure and Reading Strategy Inventory: Insights From Reading Process Research
}

\author{
George Mathew Nalliveettil \\ Department of Humanities and Sciences, Vignana Bharathi Institute of Technology, Hyderabad, India
}

\begin{abstract}
A study was conducted to explore the reading strategies of ESL (English as a Second Language) engineering students. The subjects of the study were 52 B.Tech students. The research focused on investigating the reading process of ESL students. The think-aloud procedure and reading strategy inventory were used to collect the data. Three pilot studies were conducted to validate quantitative and qualitative research procedures. A 40-item reading strategy inventory was administered to identify the engineering students' reading strategy use. The scores obtained in the reading strategy inventory has been compared to the verbal reports elicited through the think-aloud procedure. Data analysis presents an overview of the frequency of strategy use while reading an academic-related text. The paper examines the effectiveness of reading strategy inventory and think-aloud procedure for reading process research. The findings of the study discuss the data collection procedure relevant to reading process research. The study highlights challenges in validating quantitative and qualitative research procedures and suggests ways to overcome them.
\end{abstract}

Index Terms - reading strategy, reading process, think-aloud, verbal reports, reading strategy inventory

\section{INTRODUCTION}

Researchers have used quantitative and qualitative research procedures to explore reading skills and strategies of ESL (English as a Second Language) Learners. Many educational forums have discussed the process and product approaches to reading and their effectiveness in enhancing English language proficiency. In India, English being the second language, reading has become an essential part of language instruction at every level. Students have to understand that learning a language means comprehending, communicating, and thinking as they do in their mother tongue. Reading is essential inside and outside the classroom for a wide variety of purposes, and the teachers have to take enough care while imparting reading skills to the students in the classroom. This research focuses on exploring the reading strategies of ESL engineering students. Data was collected using reading strategy inventory and think-aloud verbal procedure. Pilot studies were carried out to check the validity of reading strategy inventory and think-aloud verbal procedure. This paper examines the effectiveness of the think-aloud procedure and reading strategy inventory in a reading process research.

Validating data collection procedures is a challenging task for researchers in the applied fields of study. Researchers across the world rely on quantitative and qualitative data to substantiate their research findings. There are many recommended data collection procedures in English Language Teaching (ELT), Applied Linguistics, and Classroom Research. Most universities across the world make the Research Methodology course mandatory for research scholars studying Masters or Doctoral Programmes. Some of the standard quantitative data collection procedures involve administering questionnaires, polls, surveys, and tests. Among the various qualitative data collection procedures, classroom observation and interviews are used by many researchers to authenticate their findings. Before deciding on a relevant data collection procedure, the researchers review the past and latest studies conducted in a particular field and either replicate similar procedures or modify them. Some researchers replicate research procedures that were already tested. A relevant research procedure in a specific context may not be suitable for another context either due to regional or cultural variations. In English as a Second Language (ESL) research contexts, validating research tools enhances the quality of research findings. However, some researchers do not pay much attention to validate research tools either because of time constraints or due to lack of awareness. This paper also discusses the process involved in validating research tools in an ESL research context.

\section{LITERATURE REVIEW}

\section{A. Research Procedures in L2 Reading Research}

Researchers exploring reading strategies have used questionnaires and verbal probes to uncover the strategies of ESL learners. In L2 studies, language learning inventories were administered to determine the frequency of using a particular strategy in the past (Dörnyei Zoltán, \& Taguchi, 2010, p. 5). According to Bowles (2010, p.8), in L2 research, merely relying on students' responses can be risky because it may not give much information about the cognitive processes; 
however, verbal reports enable the researchers to access the learners thought processes. Think-aloud is a qualitative approach through which the participants express their thoughts verbally during a reading activity. The reading process involves the recognition of letters, words, phrases and clauses. Since reading involves cognitive processes, such as decoding and analyzing, researchers exploring reading strategies rely on the think-aloud technique to probe the thought processes. Willis $(2004$, p. 29) believes that verbal reports are relevant for tasks that involve problem-solving and decision making. The findings of a study conducted by Nalliveettil (2014, p.47) reveal that ESL students found the think-aloud technique similar to brainstorming sessions. Elleman and Oslund (2019, P.8) reviewed existing theoretical and empirical research in reading comprehension and recommended strengthening professional development programmes and collaboration for better reading comprehension instructions. Awareness of the latest techniques in reading comprehension instruction can make the ESL teaching-learning process more interactive and productive. Since comprehension is an active process, an English teacher has to encourage the readers to engage with the text. Teachers can test the comprehension level by asking open-ended questions or collecting summaries of the assigned reading text.

A study by Pritchard (1990) utilizes culturally familiar and culturally unfamiliar passages to examine the process of how a reader activates and utilizes the relevant schema for comprehension. His study aimed to identify the strategies proficient readers use to understand culturally familiar and culturally unfamiliar passages. Pritchard's study also examines those strategies concerning the cultural backgrounds of the readers and cultural perspectives of the reading materials. His findings suggest that more idea units were recalled from the culturally familiar text in similar cultural groups. The findings of Pritchard's study reveal that when the content of reading materials changes, processing behaviour changes as well. His findings conclude that reading is a content-specific activity. Mokhtari and Reichard (2002) believe that many researchers have recognized the relevance of metacognitive awareness in reading comprehension because it differentiates skilled readers from unskilled readers. Further, Taraban et al. (2004) point out that understanding reading behaviours is necessary to consider the specific situations in which reading occurs and the reading tasks that individuals confront.

\section{B. Relevance of Strategies in Language Learning}

The term strategy has been used in many fields of study. Oxford Advanced Learners Dictionary $\left(8^{\text {th }}\right.$ edition) defines strategy as "a plan that is intended to achieve a particular purpose" (Hornby \& Turnbull, 2010). McDonough (1995) defines strategy as an articulated plan for meeting particular types of problems. Students may resort to strategy use when they encounter problems in language learning. Bialystok (1990) says that strategies are related to solutions in specific ways, and they are productive in solving the problem for reasons which theorists can articulate. She further says that strategies are systematic because the learners uncover the strategy from their knowledge of the problem and employ it systematically. Carrell (1998) points out that strategies are more efficient and developmentally advanced when generated and applied automatically as skills. According to Stern (1975), strategy is a plan for action. He further says that good language learning needs strategies of experiment and planning to develop the new language into an ordered system and revise this system progressively by constantly searching for meaning. A strategy is, therefore, a tool, plan, or method used for accomplishing a task.

Skill is the ability of a person, while strategy is a plan designed for a particular purpose. According to Carrell (1998), skills refer to information processing techniques that are automatic and applied to a text unconsciously for reasons like expertise, repeated practice, compliance with directions, luck and native use. Carrerll says that strategies are actions selected deliberately to achieve particular goals. Learning strategies are the behaviours and thoughts during a learning activity that influence an individual's encoding process (Weinstein and Mayer, 1986). According to Rubin (1987), learning strategies contribute to developing the language system that the learner constructs and directly affects his/her learning. The readers use strategies to enhance their vocabulary and sentence construction knowledge to understand varied English texts. According to Rausch (2000), the concept of learning strategies is based partly on cognitive learning theory, where learning is considered as an active, mental, learner-constructed process. O'Malley and Chamot (1990) define learning strategies as particular thoughts or behaviours that individuals use to comprehend, learn or retain new information. Lessard-Clouston (1997) says language learning strategies may be visible behaviours, steps, techniques, or invisible thoughts and mental processes and involve information and memory. Oxford (1990) divides strategies into two major classes, namely direct and indirect. According to her, language learning strategies that involve the target language are called direct strategies, and these require mental processing of the language. Oxford (1990) points out that a direct learning orientation consists of memory, cognitive and linguistic deficiency compensation strategy groups, while indirect consists of metacognitive, affective and social strategy groups. According to Rausch (2000), the direct strategies relate to retrieval of vocabulary, the identification, retention, storage, and other elements of the target language, while the indirect strategies are concerned with the management of learning and include activities like needs assessment, planning and monitoring, and outcome evaluation. Oxford (1990) subdivides direct and indirect strategies into six groups: memory, cognitive and compensation under the direct class, while under the indirect class come the metacognitive, affective and social. She says that memory strategies help learners to remember and retrieve new information.

C. Importance of Reading Strategies in Language Learning 
A reader may use different strategies to understand an academic or a non-academic related text. While reading a text, readers may consciously or unconsciously resort to strategy use when they find the text too difficult to understand. Reading comprehension results when a reader is aware of skills and strategies appropriate for the text type and understands how to apply them to accomplish the reading purpose. Reading process and comprehension are essential aspects of cognition. According to Berardo (2006), reading always has a purpose and is an integral part of everyday life. Berardo says that reading can have three primary purposes such as survival, learning or pleasure. Nel and Dreyer (2003) believe that one of the most serious problems in higher education is reading. According to Levine et al. (2000), ESL university students need to develop their reading strategies to read academic texts and advance their professional careers. Reading strategy instruction should prepare the students to understand the purpose of reading and help them select appropriate reading strategies. Nel and Dreyer (2003) point out that many students enter higher education underprepared for the reading demands that are placed on them. According to Wood et al. (1998), students often select ineffective and inefficient strategies, while Dreyer (1998) says this is due to their low reading strategy knowledge and lack of metacognitive control. Luo and Wei (2014) conducted a study using the 50-item Strategy Inventory for Language Learners (SILL) to measure self-reported use of language learning strategies. Their findings indicate the use of social strategies over metacognitive strategies in a second language immersion setting. Ozek, and Civelek (2006) recommend think-aloud protocols for observing the mental processes as they provide objective data. Qahtani (2020) employed retrospective think-aloud protocol to explore the reading strategies of EFL learners. His findings suggest that the think-aloud procedure is helpful to evaluate and reconstruct readers background knowledge.

\section{Methodology AND Questions}

\section{A. Context of the Study}

Many published research projects have discussed the effectiveness of reading skills in ESL teaching-learning contexts. However, the current study explores the reading strategies of ESL engineering students studying First Year B.Tech in engineering colleges affiliated to JNTU (Jawaharlal Nehru Technological University), India. The 52 students chosen for the study are 26 males and 26 females studying first-year B.Tech in engineering colleges affiliated to JNTU. Since English is the medium of instruction, these students are required to spend much time reading academic-related course materials written in English. It has been observed that the ESL engineering students find vocabulary and syntactic structures in the engineering textbooks difficult to comprehend. Failure to understand engineering concepts can affect their performance in internal and external assessment and job interviews.

The pre-requisite for the entrants of the engineering stream is a pass in intermediate/plus two with a specialization in Mathematics, Physics and Chemistry (MPC). These ESL engineering students are more familiar with the vocabulary related to numerical values, formulas and science-related terms. They have less exposure to the concepts related to the engineering stream. Their aim to become a software engineer or study Master of Science (MS) course often drives them to study B.Tech (Bachelor of Technology). English language communication skills that students gain during their engineering education help them communicate in social and academic situations. Also, it prepares them for their future educational and professional endeavours.

In the JNTU engineering curriculum, English is a credit course in the first semester of first-year B.Tech. Reading comprehension is a component in the English language course syllabi of first year B. Tech. The reading activities in the prescribed English textbook focus on reading techniques such as skimming, scanning, prediction, inferencing, local and global comprehension skills. These skills relate to reading, wherein students answer comprehension questions given at the end of the reading passage. Research in reading also recommends a process approach in the teaching of reading skills. The present study explores the reading strategies of ESL engineering students.

\section{B. Research Questions}

The study is based on the following research questions:

- What kind of data collection procedure is relevant for a process approach in reading skills?

- Is it necessary to compare and contrast quantitative and qualitative data to identify the reading strategies of ESL students?

- The effectiveness of reading strategy inventory and think-aloud procedure for classroom research

- What makes the quantitative and qualitative data collection procedure reliable or unreliable?

\section{Procedure}

The research progressed with a series of transitions or stages. Three pilot studies were conducted to validate the research tools for data collection. The first pilot study focused on validating the items given in a five-point scale of the reading strategy inventory. In pilot study II, the focus was on using the think-aloud technique. Since the think-aloud methodology adopted in pilot study II had drawbacks, the study was repeated. In pilot study III, a study using the thinkaloud protocol technique was repeated with certain modifications. The main study followed pilot study III, and the details of all the stages are discussed in this paper.

\section{Instrument}


Since the present research focuses on the reading strategies of engineering students, it was felt necessary to validate the data collections procedures. Hence, the available reading strategies were reviewed, and a 40-item reading strategy inventory was developed for assessing the reading strategies of first-year B. Tech students. The primary source of reading strategy inventory was the questionnaires developed by Oxford (1990), Taraban et al. (2000), Mokhtari and Reichard (2002), Taraban et al. (2004), and Mathew (2009). The subscales used in the pilot study I and the main study were similar to the reading strategy inventory developed by Mokhtari and Reichard (2002). A 40-item reading strategy inventory was developed for pilot study I. These items were categorized under three sub-scales: global reading strategies, support reading strategies, and problem-solving strategies. The items were categorized depending on the kind of strategy statement. Fourteen items were listed under global reading strategies, fourteen listed under support reading strategies, and twelve listed under problem-solving strategies. Under each given statement in the reading strategy inventory, a 5-point scale range is given to describe each item.

\section{E. A Description of the Scoring Pattern in the Reading Strategy Inventory}

From the pilot study I, it was observed that the classification of items would be more appropriate for our study. Since ten more items were added to the 30-item reading strategy inventory developed by Mokhtari and Reichard (2002), it was felt that the edited list of 40-item reading strategy inventory gave additional information related to reading strategies. Students also responded to the five-point scale given in the reading strategy inventory. Students were asked to read each statement and rate how often they use the strategy described in the statement using a 5-point scale range. The individual scores obtained in each item were added to obtain a total score. The average response for the sub-scale global reading strategy was obtained by taking the total score obtained in all the items of the sub-scales and dividing it by the number of items. The same procedure was followed to get an average response in support and problem-solving reading strategies. The total scores obtained from each strategy subscale, namely global, support and problem-solving reading strategy, were added and then divided with the total number of items to get an average response of the entire inventory. The interpretation of these scores is derived from the interpretation scheme used by Mokhtari and Reichard (2002). While examining the reading strategy usage of individual and groups of students on the reading strategy inventory, which ranges from 1 to 5, three levels of usage were identified, as suggested by Oxford (1990) and Mokhtari and Reichard (2002). For language learning strategy usage: "high (mean of 3.5 or higher), medium (mean of 2.5 to 3.4 ) and low (2.4 or lower)" (Oxford, 1990; Mokhtari and Reichard, 2002). These usage levels provide a helpful standard that can be used for interpreting the score averages obtained by individuals or groups of students (Oxford, 1990; Mokhtari and Reichard, 2002).

\section{F. The Process of Validating Quantitative Data}

It was necessary to determine whether the engineering students understood the strategy statements in the reading strategy inventory. So, a pilot study was conducted in engineering colleges affiliated to JNTU and Osmania University. The two sets of reading strategy inventory administered to the students were the 30-item inventory developed by Mokhtari and Reichard (2002) and the 40-item edited version of reading strategy inventory based on the works of Oxford, (1990), Taraban et al. (2000), Mokhtari and Reichard (2002), and Taraban et al. (2004). In the edited version, some items were added, and some items were modified for clarity. A study on the reading strategy inventory developed by Mokhtari and Reichard (2002) and the edited version was found necessary because it would reveal which inventory best suits the future investigations on reading strategies.

\section{G. Pilot Study I}

As mentioned in the earlier section, to test the reliability of the reading strategy inventory, a preliminary pilot study was conducted in engineering colleges affiliated to JNTU and Osmania University. The reading strategy inventory was administered to six first-year B.Tech students (three boys and three girls). The findings from the preliminary study suggested that the 40-item reading strategy inventory can be administered to engineering students. However, the findings suggested that reading strategy inventory, a self-report instrument, reveals only the students' perceptions about their reading strategies. Mokhtari and Reichard (2002) caution that the best possible use of these strategies will ultimately depend, to a great extent, on students' age, their reading ability, text difficulty, type of material read, and other related factors. For this reason, more related resources on reading strategies were reviewed. A review of literature related to the think-aloud technique and retrospective probe indicated that these research tools could provide more insights into the reading process. Since these techniques give scope for individual verbal responses, a pilot study was conducted to determine whether it would give the required data for the research.

\section{H. Think-aloud Procedure}

Think-aloud probe based on the work of Nielson (1994), Singhal (2001) and Thompson et al. (2006) was used to get insights into the reading processes of engineering students. A pilot study was conducted to test whether the think-aloud technique would give insights into the reading strategies. Garner (1987) suggested that the researcher has to provide a task in the think-aloud method and ask the subjects to say aloud everything they think and everything that occurs to them while performing a task. 
The relevance of the think-aloud probe as a research tool was tested through reading passages chosen from the prescribed textbooks. A reading passage was taken from the prescribed English coursebook of the first year B. Tech and the second reading passage was from an engineering text. The subjects for pilot study II were twelve students (six boys and six girls) of first-year B.Tech from engineering colleges affiliated to JNTU. Students' permission was sought, and the think-aloud verbal interview was recorded. Each student was asked to read the passage. Immediately after reading the passage, the student was subjected to the think-aloud verbal probe to elicit information on his/her reading process. Students were allowed to look into the given reading passage as and when required. Students were allowed to read the text as and when they felt it necessary. Students were allowed to respond by reading the text as it would give more insights into their reading process. The same procedure was used to elicit the students' responses from both the reading passages.

\section{Re-validating the Qualitative Research Procedure: Pilot Study II}

The preliminary research findings (pilot study II) on the think-aloud procedure further suggest that the methodology needed to be modified for eliciting relevant responses related to the reading process. It was observed that the researcher was focusing on think-aloud questions that were recommended by Nielson (1994), Singhal (2001) and Thompson et al. (2006) and thus was repeatedly asking pointed questions that they suggested. For this reason, the drawbacks of the think-aloud verbal interview were closely examined and thus modified the think-aloud approach. The findings of pilot study II suggest that familiar texts do not give much insight into the reading process, and too much technical jargon would make the text difficult to understand. For this reason, the study was repeated using semi-technical texts.

\section{G. Pilot Study III}

It was decided to repeat the field study using a think-aloud procedure with a modified approach, so pilot study III was conducted to clarify the relevance of the research tool. Two semi-technical reading passages were selected, and the think-aloud procedure was used to elicit responses from the students. The study was conducted on six engineering students (three boys and three girls) studying first-year B.Tech in engineering colleges affiliated to JNTU. Students were interviewed individually, and their responses were recorded. Each student was asked to read the passage silently, and after having read the complete passage, the student had to report to the researcher. The same method was used to elicit responses on the second reading passage. The researcher asked open-ended questions relating to the text and individual student's understanding of the reading passage. The students were encouraged to express their thought processes verbally while reading the text. The students were also allowed to skim or scan through the given passages when they felt it necessary. They were encouraged to express their thought processes verbally while reading the text. Their responses were recorded and later transcribed as these would give information about how the students are processing a text. The findings of pilot study III indicate that the modified think-aloud approach is relevant to probe into the reading process of ESL engineering students.

\section{K. The Procedure of the Main Study}

Since the think-aloud probe requires individual attention, the researcher had to give individual attention to all the 52 engineering students. The researcher had a detailed interview with individual students throughout the study, which lasted more than an hour each, and their verbal responses were recorded. A few think-aloud questions were scripted based on pilot studies II and III, while most of them were designed by the researcher as needed during the interview session. The point of these probes was to allow the interviewer to explore beyond what the respondent says or does not say without increasing the chances of invalid or reactive reports. Think-aloud questions were used to probe for additional evidence beyond what respondents report spontaneously. This probe was used to make the students report on the components of high-level mental processes, like the sequence of steps that leads to the solution of a problem. Students were also asked to express their thoughts verbally as they read the text.

Ericsson and Simon (1980) argue that when verbal reports are collected with other records of behaviour, the consistency of results can be checked. Schoenfeld (1985) contend that verbal data should be compared and contrasted with data from other sources. For these reasons, the think-aloud verbal probe and the 40-item reading strategy inventory were used to identify the ESL engineering students' reading strategies.

\section{RESULTS AND ANALYSIS}

An analysis of the think-aloud verbal procedure, the reading strategy inventory scores, including the similarities and variations in the use of reading strategies, are presented in this section. The data recorded using the think-aloud procedure is analyzed based on Nalliveettil (2014) categorization: successful readers, partly successful readers, and unsuccessful readers. Successful readers could comprehend the complete text, while partly successful readers could comprehend parts of the text and unsuccessful readers failed to comprehend the text.

\section{A. Analysis of Verbal Reports}

The data analysis of the think-aloud procedure is presented in Tables 1,2 and 3 
TABLE 1

AN OVERVIEW OF VERBAL REPORT

\begin{tabular}{|c|c|c|c|c|c|}
\hline Student No. & Gender & $\begin{array}{l}\text { No. of times } \\
\text { strategy used }\end{array}$ & Student No. & Gender & $\begin{array}{l}\text { No. of times } \\
\text { strategy used }\end{array}$ \\
\hline 1. & Female & 07 & 27. & Male & 09 \\
\hline 2. & Male & 18 & 28. & Male & 04 \\
\hline 3. & Male & 01 & 29. & Female & 03 \\
\hline 4. & Female & 05 & 30. & Male & 04 \\
\hline 5. & Male & 01 & 31. & Female & 05 \\
\hline 6. & Female & 02 & 32. & Male & 11 \\
\hline 7. & Female & 05 & 33. & Male & 01 \\
\hline 8. & Male & 03 & 34. & Male & 11 \\
\hline 9. & Female & 02 & 35. & Male & Nil \\
\hline 10. & Female & 04 & 36. & Female & 03 \\
\hline 11. & Male & Nil & 37. & Male & 12 \\
\hline 12. & Male & 05 & 38. & Female & 03 \\
\hline 13. & Female & 04 & 39. & Female & 04 \\
\hline 14. & Male & 09 & 40. & Male & 05 \\
\hline 15. & Female & 15 & 41. & Male & 06 \\
\hline 16. & Male & 07 & 42. & Female & Nil \\
\hline 17. & Male & 04 & 43. & Female & 05 \\
\hline 18. & Male & 06 & 44. & Female & 07 \\
\hline 19. & Female & Nil & 45. & Male & 02 \\
\hline 20. & Female & 02 & 46. & Male & Nil \\
\hline 21. & Male & 08 & 47. & Male & 03 \\
\hline 22. & Female & Nil & 48. & Male & 22 \\
\hline 23. & Male & 02 & 49. & Female & 07 \\
\hline 24. & Female & Nil & 50. & Female & Nil \\
\hline 25. & Female & 05 & 51. & Female & Nil \\
\hline 26. & Female & 10 & 52. & Female & 09 \\
\hline
\end{tabular}

An analysis of the data in Table 2 indicates that Student No.48 (Male) used global, support, and problem-solving strategies (22 times) to comprehend the text. Nine students could not use any of the strategies.

\section{B. Analysis of Reading Strategy Inventory}

A reading strategy inventory was administered after the verbal interview. The reading strategy usage of individual and groups was examined in 5- point scale ranging from 1 (I never do this) to 5 (I always do this), and three levels of usage were identified, as suggested by Oxford (1990), for language learning strategy usage: high (mean of 3.5 or higher), medium (mean of 2.5 to 3.4) and low (2.4 or lower). The table below presents the average mean of student 1 to student 52. The sequencing is the same as the sequencing of students in the think-aloud verbal probe. The average mean of all the students in global strategies, support strategies and problem-solving reading strategies is given below: 
TABLE 2

READING STRATEGY INVENTORY SCORES

\begin{tabular}{|c|c|c|c|c|c|c|c|}
\hline $\begin{array}{c}\text { Student } \\
\text { No. }\end{array}$ & $\begin{array}{c}\text { Global } \\
\text { Problem }\end{array}$ & Support & $\begin{array}{c}\text { Problem } \\
\text { Solving }\end{array}$ & $\begin{array}{c}\text { Student } \\
\text { No. }\end{array}$ & $\begin{array}{c}\text { Global } \\
\text { Problem }\end{array}$ & Support & $\begin{array}{c}\text { Problem } \\
\text { Solving }\end{array}$ \\
\hline S1-F & 3.85 & 3.71 & 4.08 & S27-M & 4.07 & 4.21 & 4.16 \\
\hline S2-M & 3.78 & 3.5 & 3.91 & S28-M & 3.35 & 4.0 & 4.08 \\
\hline S3-M & 1.85 & 2.21 & 1.91 & S29-F & 3.85 & 4.07 & 4.33 \\
\hline S4-F & 4.57 & 4.28 & 4.5 & S30-M & 3.78 & 3.21 & 4.16 \\
\hline S5-M & 3.92 & 3.71 & 4.33 & S31-F & 4.0 & 3.71 & 3.58 \\
\hline S6-F & 3.35 & 3.78 & 4.16 & S32-M & 3.64 & 4.07 & 4.66 \\
\hline S7-F & 3.5 & 3.21 & 4.16 & S33-M & 3.64 & 3.71 & 4.25 \\
\hline S8-M & 2.71 & 4.0 & 4.0 & S34-M & 4.07 & 4.14 & 4.33 \\
\hline S9-F & 3.57 & 4.64 & 3.25 & S35-M & 3.57 & 3.64 & 3.91 \\
\hline S10-F & 3.14 & 3.85 & 3.66 & S36-F & 4.35 & 4.5 & 4.16 \\
\hline S11-M & 3.28 & 3.64 & 4.08 & S37-M & 3.85 & 4.0 & 4.08 \\
\hline S12-M & 3.92 & 3.0 & 3.16 & S38-F & 3.78 & 3.42 & 3.58 \\
\hline S13-F & 4.42 & 4.92 & 5.0 & S39-F & 3.42 & 3.28 & 3.25 \\
\hline S14-M & 3.85 & 4.21 & 3.66 & S40-M & 3.71 & 3.28 & 3.75 \\
\hline S15-F & 3.71 & 3.07 & 3.66 & S41-M & 3.64 & 4.0 & 4.33 \\
\hline S16-M & 3.57 & 3.57 & 3.83 & S42-M & 3.14 & 4.42 & 3.25 \\
\hline S17-M & 3.42 & 3.42 & 3.5 & S43-F & 4.35 & 4.71 & 4.41 \\
\hline S18-M & 4.28 & 3.92 & 4.25 & S44-F & 4.07 & 3.64 & 3.91 \\
\hline S19-F & 3.5 & 3.28 & 3.75 & S45-M & 3.5 & 3.42 & 4.66 \\
\hline S20-F & 3.78 & 4.0 & 4.0 & S46-M & 3.42 & 4.14 & 3.58 \\
\hline S21-M & 3.57 & 4.0 & 4.16 & S47-M & 2.78 & 2.85 & 3.0 \\
\hline S22-F & 3.71 & 4.42 & 4.16 & S48-M & 4.21 & 3.64 & 4.58 \\
\hline S23-M & 3.14 & 3.21 & 3.14 & S49-F & 3.35 & 2.28 & 2.25 \\
\hline S24-F & 3.64 & 3.50 & 3.33 & S50-F & 3.64 & 3.35 & 3.83 \\
\hline S25-F & 4.0 & 3.78 & 3.83 & S51-F & 4.07 & 4.07 & 4.0 \\
\hline S26-F & 3.78 & 3.64 & 3.41 & S52-F & 3.64 & 3.35 & 3.83 \\
\hline
\end{tabular}

Mean Scores

Total Number of all Students $=52$

Number of Items $=40$

Total Number of Students X Number of Items $(52$ X 40) $=2080$

Total Score $=7781$

$7781 / 2080$

- The mean of all students in global, support and problem-solving strategies is 3.74

Therefore, the overall mean of all students is in the category 'high'. Although the overall mean of all the students is in the higher range, the scores were not uniform across global, support and problem-solving strategies. Of the 52 students, the mean of 30 students was uniform in global, support and problem-solving strategies. The mean of 22 students in global, support and problem-solving strategies were in different ranges. Following are the details of the 30 students whose mean scores were on the uniform scale.

- 26 students are on the scale of 3.5 and higher in global, support and problem-solving strategies. Their average mean is 3.87 .

- 3 students are on a scale of 2.5 to 3.4. Their average mean is 2.95 .

- 1 student is on a scale of 2.4 and lower. His average mean is 2.0.

It was observed that a majority of the students are in the high range.

Mean scores in global strategies

- The overall mean of 39 students in global reading strategies is 3.5 or higher. Their average mean is 3.85 .

- The overall mean of 12 students is on a scale of 2.5 and 3.4. Their mean is 3.21

- The overall mean of 1 student is on a scale of 2.4 or lower. His average mean is 1.85

Mean scores in support strategies

- The overall mean of 36 students is 3.5 and higher in support reading strategies. Their mean is 3.99.

- The overall mean of 14 students is on a scale of 2.5 and 3.4. in support reading strategies. Their mean is 3.24 .

- The overall mean of 2 students is below the scale of 2.4 or lower in support reading strategies. Their average mean is 2.25 .

Mean scores in problem-solving strategies

- The overall mean of 41 students in problem-solving reading strategies is 3.5 and higher. Their mean is 4.0.

- The overall mean of 9 students in a scale of 2.5 and 3.4 in support reading strategies. Their mean is 3.17 .

- The overall mean of 2 students in problem-solving reading strategies is in a scale of 2.4 or lower. Their mean score is 2.08 


\section{A Comparative Analysis of Verbal Data and the Scores of Reading Strategy Inventory}

The given data indicates the students' use of reading strategies while reading academic-related materials. A reading strategy inventory was administered immediately after the think-aloud verbal interview. The students were instructed to read each statement and rate how often they use the strategy described in that statement using a 5-point scale ranging from 1 (I never do this) to 5 (I always do this). The students were reminded that their responses should refer only to strategies they use when reading college-related materials.

An analysis of the students' verbal report while reading an academic-related text and the average scores in the subscales of all the successful students and some of the partly successful readers in global, support and problem-solving reading strategies indicate similarities in the use of reading strategies. The reading strategy inventory scores of some of the partly successful readers and most unsuccessful readers show variations in the use of reading strategies.

D. Similarities of Reading Strategies in Verbal Reports and Reading Strategy Inventory of Successful Readers

TABLE 3

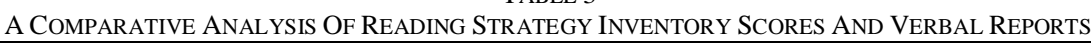

\begin{tabular}{|c|c|c|c|c|c|}
\hline S1. No & Student No. & \multicolumn{3}{c|}{$\begin{array}{c}\text { Reading Strategy Inventory Score } \\
\text { Global }\end{array}$} & $\begin{array}{c}\text { Support } \\
\text { Solving }\end{array}$ \\
& & & & $\begin{array}{c}\text { Verbal Reports } \\
\text { Po. of times strategy used }\end{array}$ \\
\hline 1 & S1- Female & 3.85 & 3.71 & 4.08 & 07 \\
\hline 2 & S2-Male & 3.78 & 3.5 & 3.91 & 18 \\
\hline 3 & S4-Female & 4.57 & 4.28 & 4.5 & 05 \\
\hline 4 & S14-Male & 3.85 & 4.21 & 3.66 & 09 \\
\hline 5 & S15-Female & 3.71 & 3.07 & 3.66 & 15 \\
\hline 6 & S21-Male & 3.57 & 4.0 & 4.16 & 08 \\
\hline 7 & S25-Female & 4.0 & 3.78 & 3.83 & 05 \\
\hline 8 & S26-Female & 3.78 & 3.64 & 3.41 & 10 \\
\hline 9 & S27-Male & 4.07 & 4.21 & 4.16 & 11 \\
\hline 10 & S32-Male & 3.64 & 4.07 & 4.66 & 11 \\
\hline 11 & S34-Male & 4.07 & 4.14 & 4.33 & 12 \\
\hline 12 & S37-Male & 3.85 & 4.0 & 4.08 & 05 \\
\hline 13 & S40-Male & 3.71 & 3.28 & 3.75 & 05 \\
\hline 14 & S43-Female & 4.35 & 4.71 & 4.41 & 22 \\
\hline 15 & S48-Male & 4.21 & 3.64 & 4.58 & 09 \\
\hline 16 & S52-Female & 3.64 & 3.35 & 3.83 & \\
\hline
\end{tabular}

The verbal reports and the reading strategy inventory scores of all (16 students) successful readers while reading an academic-related text show similarity in the use of global, support and problem-solving reading strategies.

\section{E. Similarities of Reading Strategies in Verbal Reports and Reading Strategy Inventory of Partly Successful Readers}

An analysis of the verbal report data and the average mean scores in the reading strategy inventory of partly successful readers indicates similarities as well as variations in the use of reading strategies. However, most of the students' verbal data and scores of the sub-scales global, support and problem-solving reading strategy inventory show similarities in the partial use of reading strategies.

TABLE 4

A COMPARATIVE ANALYSIS OF READING STRATEGY INVENTORY SCORES AND VERBAL REPORTS

\begin{tabular}{|c|c|c|c|c|c|}
\hline \multirow[t]{2}{*}{ SI. No } & \multirow[t]{2}{*}{ Student No. } & \multicolumn{3}{|c|}{ Reading Strategy Inventory } & \multirow{2}{*}{$\begin{array}{l}\text { Verbal Reports } \\
\text { No. of times strategy used }\end{array}$} \\
\hline & & Global & $\begin{array}{c}\text { Score } \\
\text { Support } \\
\text { solving }\end{array}$ & Problem & \\
\hline 1 & S7-Female & 3.5 & 3.21 & 4.16 & 05 \\
\hline 2 & S8-Male & 2.71 & 4.0 & 4.0 & 03 \\
\hline 3 & S10 Female & 3.14 & 3.85 & 3.66 & 04 \\
\hline 4 & S12-Male & 3.92 & 3.0 & 3.16 & 05 \\
\hline 5 & S16-Male & 3.57 & 3.57 & 3.83 & 07 \\
\hline 6 & S17-Male & 3.42 & 3.42 & 3.5 & 04 \\
\hline 7 & S18-Male & 4.28 & 3.92 & 4.25 & 06 \\
\hline 8 & S28-Male & 3.35 & 4.0 & 4.08 & 04 \\
\hline 9 & S29-Female & 3.85 & 4.07 & 4.33 & 03 \\
\hline 10 & S30-Male & 3.78 & 3.21 & 4.16 & 04 \\
\hline 11 & S31-Female & 4.0 & 3.71 & 3.58 & 05 \\
\hline 12 & S38-Female & 3.78 & 3.42 & 3.58 & 03 \\
\hline 13 & S39-Female & 3.42 & 3.28 & 3.25 & 04 \\
\hline 14 & S41-Male & 3.64 & 4.0 & 4.33 & 06 \\
\hline 15 & S44-Female & 4.07 & 3.64 & 3.91 & 07 \\
\hline 16 & S47-Male & 2.78 & 2.85 & 3.0 & 03 \\
\hline 17 & S49-Female & 3.35 & 2.28 & 2.25 & 07 \\
\hline
\end{tabular}


The verbal reports and the scores of the reading strategy inventory of seventeen partly successful readers show similarities in the use of reading strategies.

\section{F. Similarities in the Use of Reading Strategies in Verbal Reports and Reading Strategy Inventory of Unsuccessful Readers}

An analysis of verbal report data and the average mean scores of reading strategy inventory indicate that some students are unsuccessful in using reading strategies while reading an academic-related text. The verbal data and the average mean in the sub-scales of global, support and problem-solving reading strategy inventory of an unsuccessful reader show similarities.

TABLE 5

A COMPARATIVE ANALYSIS OF READING STRATEGY INVENTORY SCORES AND VERBAL REPORTS

\begin{tabular}{|c|c|c|c|c|c|}
\hline \multirow[t]{2}{*}{ Sl. No } & \multirow[t]{2}{*}{ Student No. } & \multicolumn{3}{|c|}{ Reading Strategy Inventory Score } & \multirow{2}{*}{$\begin{array}{c}\text { Verbal Reports } \\
\text { No. of times strategy used }\end{array}$} \\
\hline & & Global & $\begin{array}{l}\text { Support } \\
\text { Solving } \\
\end{array}$ & Problem & \\
\hline 1 & S3-Male & 1.85 & 2.21 & 1.91 & 01 \\
\hline
\end{tabular}

Only one unsuccessful student's verbal reports and reading strategy inventory scores show similarities as he was unsuccessful in using the reading strategies. The rest of the unsuccessful readers' verbal reports and reading strategy inventory scores do not show similarities. Their reading strategy inventory scores show high use of strategies, while the verbal reports indicate that most of these readers failed to use strategies while reading an academic-related text.

\section{G. Variations in the Use of Reading Strategies in Verbal Reports and Reading Strategy Inventory Scores}

An analysis of the verbal report data and the average scores in the reading strategy inventory reveal variations in the use of reading strategies by partly successful and unsuccessful readers. The variations are visible in the verbal reports and in the average scores of global, support and problem-solving reading strategy inventory sub-scales.

TABLE 6

A COMPARATIVE ANALYSIS OF READING STRATEGY INVENTORY SCORES AND VERBAL REPORTS

\begin{tabular}{|c|c|c|c|c|c|}
\hline \multirow[t]{2}{*}{ Sl. No } & \multirow[t]{2}{*}{ Student No. } & \multicolumn{3}{|c|}{ Reading Strategy Inventory Score } & \multirow{2}{*}{$\begin{array}{l}\text { Verbal Reports } \\
\text { Strategies Used }\end{array}$} \\
\hline & & & $\begin{array}{l}\text { Suppor } \\
\text { solving }\end{array}$ & Problem & \\
\hline 1 & S5-Male & 3.92 & 3.71 & 4.33 & 01 \\
\hline 3 & S9-Female & 3.57 & 4.64 & 3.25 & 02 \\
\hline 4 & S11-Male & 3.28 & 3.64 & 4.08 & Nil \\
\hline 5 & S13-Female & 4.42 & 4.92 & 5.0 & 04 \\
\hline 7 & S20-Female & 3.78 & 4.0 & 4.0 & 02 \\
\hline 8 & S22-Female & 3.71 & 4.42 & 4.16 & Nil \\
\hline 9 & S23-Male & 3.14 & 3.21 & 3.14 & 02 \\
\hline 10 & S24-Female & 3.64 & 3.50 & 3.33 & Nil \\
\hline 11 & S33-Male & 3.64 & 3.71 & 4.25 & 01 \\
\hline 12 & S35-Male & 3.57 & 3.64 & 3.91 & Nil \\
\hline 16 & S46-Male & 3.42 & 4.14 & 3.58 & Nil \\
\hline 17 & S50-Female & 3.64 & 3.35 & 3.83 & Nil \\
\hline 18 & S51-Female & 4.07 & 4.07 & 4.0 & Nil \\
\hline
\end{tabular}

As observed in the table above, the reading strategy inventory scores and the verbal reports of 18 students show dissimilarities in the use of reading strategies.

The findings suggest that verbal reports and reading strategy inventory scores of thirty-four (34) students were similar in the use of reading strategies. In contrast, the verbal reports and the reading strategy inventory scores of the remaining eighteen (18) students show variations. These variations in verbal reports and reading strategy inventory scores were in responses of the partly successful and unsuccessful readers.

\section{DISCUSSION}

Researchers in the past relied on quantitative and qualitative data to identify the reading strategies of ESL students. However, not many studies in reading strategy research have compared the effectiveness of data collection procedures. It is observed that researchers who investigated the reading process have based their findings using either a quantitative or qualitative approach. However, the findings of this study are based on an in-depth analysis of quantitative and qualitative data. The findings reveal that it is necessary to compare and contrast quantitative and qualitative data. The data from the reading strategy inventory has been compared with the data elicited using the think-aloud verbal procedure. This study followed Nalliveettil's (2014) classification model and categorized students as successful, partly 
successful and unsuccessful strategy users. It has been observed that the reading strategy inventory scores of partly successful students show similarities and variations in the use of reading strategies. An analysis of the reading strategy inventory scores and verbal reports indicates that the frequency of strategy use and mean scores of successful readers indicate a higher use of reading strategies. The similarities in the frequency of strategy use found in the verbal reports and reading strategy inventory sores of sixteen successful readers, seventeen partly successful and one unsuccessful reader suggest the effectiveness of research tools in generating valid data. However, the reading strategy inventory scores and the verbal reports of the eighteen students show dissimilarities in the frequency of strategy use. The scores indicate a higher use of reading strategies. In contrast, the data from the verbal reports indicate that these eighteen students did not use the strategies to the frequency that was reported in the reading strategy inventory. The dissimilarities in the use of strategies could be identified because of comparing the quantitative and qualitative data. The findings of the study suggest that research tools have the potential to provide invalid data. It is observed that depending solely on quantitative data provides information about the students' perceptions of strategies rather than their actual use of such strategies in a given reading context.

The think-aloud procedure as a qualitative research tool has been useful to probe into the ESL engineering students' actual reading strategy use in a given reading context. Even though the large amounts of data generated using this procedure poses a challenge to the researchers, it accounts for the validity of data in researching the reading process of engineering students. A close examination of verbal reports indicated that most of the strategies reported by the ESL engineering students in their verbal reports were similar to the 30-item reading strategy inventory model developed by Mokhtari and Reichard (2002) and the 40-item reading strategy inventory developed for this study. The recorded verbal data in the audio format requires careful listening and meticulous transcription into a written form. Transcribing the verbal data into a written form is tedious process and time-consuming. Another challenge for researchers is to quantify the qualitative data. In order to quantify the verbal data, the questionnaires developed by Oxford (1990), Taraban et al. (2000), Mokhtari and Reichard (2002), and Taraban et al. (2004) was found relevant.

The validity of reading strategy inventory as a research tool was tested before administering it in the main study. The findings highlight the need to validate the questionnaires through pilot studies. The pilot study examined the students' ability to comprehend each of the given strategy items. Even though the results of the pilot study proved that statements given in the reading strategy inventory are comprehensible to the students, a comparison of scores in reading strategy inventory and the frequency of strategy use in verbal reports of the main study show variations. Based on the uniformity of scores of the reading strategy inventory and verbal reports, the accuracy rating of the reading strategy inventory as a research tool is $65 \%$. A mismatch in the reading strategy inventory scores and the frequency of strategy use in the verbal reports of 18 students (35\%) indicate how perception differs from reality. These ESL students perceived that they are competent users of reading strategies while the same competency is not reflected in their verbal reports. As observed in this study, the self-inflated scores can provide invalid results, and the findings of the study support the views of Ericsson and Simon (1980) and Schoenfeld (1985) that consistency of results has to be checked by comparing and contrasting the data with other sources. In order to achieve consistency in results, researchers investigating the cognitive processes have to use self-measuring reports that can generate factual and observable data. Many researchers administer self-evaluation questionnaires wherein the respondents must choose a rating scale that best fits their personality. Rating scales such as 1 (I never or almost never do this) to 5 (I always or almost always do this) used in the reading strategy inventory as a parameter to evaluate an individual's self-competence or self-awareness can, sometimes, pose confusion if each of the scales is not explicitly made clear in a research context.

The findings of the study suggest that the think-aloud procedure is a useful technique to uncover the reading strategies of ESL engineering students. The inadequacies of quantitative data are compensated when the qualitative data has the potential to address such shortcomings. The think-aloud procedure and reading strategy inventory focused on eliciting information related to the reading process of ESL engineering students. The think-aloud procedure allowed the students to verbally state the strategies that were used to comprehend words, phrases and sentences while reading an academic text. During the reading process, students were made conscious of their thinking processes and procedures that helped or hindered their comprehension of words, phrases and sentences. When a student could not comprehend a word, phrase or sentence, the think-aloud made him/her realize the reasons behind such impediments. The findings of the study reveal the effectiveness of qualitative research procedures to probe into difficult areas where quantitative research techniques may not provide accurate results. However, it was observed that the reading strategy inventory was useful to elicit ESL engineering students' perceptions of reading strategy use. Exposure to the 40-item reading strategy inventory made the students conscious of strategy use while reading academic-related texts. Quantitative data gathered through questionnaires can provide a lot of valid information, which is otherwise difficult to collect using qualitative research procedures. The findings of the study are limited to the ESL teaching-learning contexts with a specific focus on engineering undergraduates. However, the quantitative and qualitative research procedure followed in this study can be applied to other ESL/EFL research contexts where reading processes are investigated.

\section{CONCLUSION}

The study examined the effectiveness of the think-aloud procedure and reading strategy inventory in ESL reading process research. Adopting research procedures without field-testing their effectiveness can sometimes lead to 
inaccurate results and findings. A thorough analysis of the data collection procedures at each of the stages during the progression of the research makes this study significant in ESL research contexts. Pilot studies were undertaken to examine the validity of the think-aloud procedure and reading strategy inventory. The findings of the pilot studies gave an impetus to the main study. Validating research procedures enhances authenticity in research findings. The data that a researcher collects from various sources determines the quality of a particular research design. When the research findings are based on primary sources, there is a need to adopt a suitable methodology to elicit data or else it can lead to falsified results. The findings suggest that a researcher must be cautious while adopting a research procedure to generate qualitative or quantitative data.

\section{REFERENCES}

[1] Berardo, S. A. (2006). The use of authentic materials in the teaching of reading. The Reading Matrix, 6(2), 60-69.

[2] Bialystok, E. (1990). Communication strategies: A psychological analysis of second language Use. Oxford: Basil Blackwell.

[3] Bowles, M. A. (2010). The think-aloud controversy in second language research. Routledge.

[4] Carrell, P. L. (1998). Can reading strategies be successfully taught?. Australian review of applied Linguistics, 21(1), 1-20.

[5] Dreyer, C. (1998). Improving students' reading comprehension by means of strategy instruction. Journal of Language Teaching, 31(1), 18-29.

[6] Dörnyei Zoltán, \& Taguchi, T. (2010). Questionnaires in second language research: construction, administration, and processing. Routledge: New York

[7] Elleman, A. M., \& Oslund, E. L. (2019). Reading comprehension research: Implications for practice and policy. Policy Insights from the Behavioral and Brain Sciences, 6(1), 3-11.

[8] Garner, R (1987). Metacognition and reading comprehension. Norwood, NJ: Ablex Publishing.

[9] Hornby, A. S., \& Turnbull, J. (2010). Oxford advanced learner's dictionary of current English (8th edition.). Oxford: Oxford University Press.

[10] Lessard-Clouston, M. (1997). Language learning strategies: An overview for L2 teachers. The internet TESL journal, 3(12), 6980.

[11] Levine, A., Ferenz, O., \& Reves, T. (2000). EFL academic reading and modern technology: How can we turn our students into independent critical readers. TESL-EJ, 4(4), 1-9.

[12] Luo, J., \& Wei, N. (2014). Language learning strategy use in an American IEP: Implications for EFL. The Asian EFL Journal, 16(3), 96-115.

[13] Mathew, N. G. (2009). A study of the English language reading strategies of engineering students in colleges affiliated to JNTU, Andhra Pradesh (unpublished PhD dissertation). India: University of Hyderabad.

[14] McDonough, S. H. (1995). Strategy and skill in learning a foreign language. Edward Arnold: London.

[15] Mokhtari, K., \& Reichard. C. (2002). Assessing students' metacognitive awareness of reading strategies inventory. Journal of Education Psychology, 94, 249-259.

[16] Nalliveettil, G. M. (2014). Assessing reading strategies of engineering Students: Think aloud approach. English Language Teaching, 7(5), 38-49.

[17] Nel, C and Carisma Dreyer. (2003). Teaching reading strategies and reading comprehension within a technology-enhanced learning environment. System, 31, 349-365.

[18] Nielson, J. (1994). Estimating the number of subjects needed for a thinking aloud test. International Journal of HumanComputer Studies, 41 (3), 385-397.

[19] O'Malley, J. M and Chamot, A.U. (1990). Learning strategies in second language acquisition. New York: Cambridge University Press

[20] Oxford, R. L. (1990). Language learning strategies: What every teacher should know. Boston: Heinle and Heinle.

[21] Ozek, Y., \& Civelek, M. (2006). A study on the use of cognitive reading strategies by ELT students. The Asian EFL Journal, 14, 1-26.

[22] Pritchard, R. (1990). The effects of cultural schemata on reading processing strategies. Reading Research Quarterly, 24, 273295.

[23] Qahtani, A. A. AI. (2020). Exploring reading strategies through introspective and retrospective think aloud protocol. TESOL International Journal, 15(4), 37-63.

[24] Rausch, A. S. (2000). Language learning strategies instruction and language use applied to foreign Language reading and writing: A simplified "menu" approach. Retrieved on June 18, 2021 from Literary Across Cultures Website. URL: http://www2.aasa.ac.jp/ dcdycus/LAC2000/rausch.htm

[25] Rubin, J. (1987). Learner strategies: Theoretical assumptions, research history and typology. In A. Wenden and J. Rubin (Eds.), Learner strategies and language learning. Englewood Cliffs, NJ: Prentice Hall.

[26] Singhal, M. (2001). Reading proficiency, reading strategies, metacognitive awareness and L2 readers. The Reading Matrix, 1(1), $1-15$.

[27] Stern, H. H. (1975). What can we learn from the good language learner? Canadian Modern Language Review, 31, $304-318$.

[28] Taraban, R., Kerr, M., \& Rynearson, K. (2004). Analytic and pragmatic factors in college students' metacognitive reading strategies. Reading Psychology, 25(2), 67-81.

[29] Taraban, R., Rynearson, K., \& Kerr, M. (2000). College students' academic performance and self-reports of comprehension strategy use. Reading Psychology, 21(4), 283-308.

[30] Thompson, S., Bottsford-Miller, N., \& Johnstone, C. (2006). Using the think aloud method (cognitive labs) to evaluate test design for students with disabilities and English language learners (NCEO Technical Report).

[31] Weinstein, C., and Mayer, R. (1986). The teaching of learning strategies. In M.C. Wittrock (Ed.), Handbook of Research on Teaching, 3rd Edition. New York: Macmillan. 
[32] Wood, E, Motz. M and Willoughby. T. (1998). Examining students' retrospective memories of strategy development. Journal of Educational Psychology, 90, 698-704.

[33] Willis, G. B (2004). Cognitive interviewing revisited: A useful technique, in theory? In S. Pressser (Ed.), Methods for testing and evaluating survey questionnaires (pp. 23-43). Wiley-Interscience.

George Mathew Nalliveettil is an Associate Professor at Vignana Bharathi Institute of Technology, Hyderabad, India. He has been teaching English, Soft Skills and Business communication to ESL and EFL undergraduates. His research interests include English Language Teaching, Semantics, Language Testing, Curriculum Development and Second Language Learning. https://orcid.org/0000-0001-8163-1485, Scopus Author ID: 56114881600 